\title{
Sanitation predictors of childhood morbidities in Ethiopia: evidence from Dabat Health and Demographic Surveillance System
}

Zemichael Gizaw ${ }^{1 *}$ (D), Gashaw Andargie Biks ${ }^{2,5}$, Mezgebu Yitayal ${ }^{2,5}$, Geta Asrade Alemayehu², Kassahun Alemu ${ }^{3,5}$, Tadesse Awoke ${ }^{3,5}$, Adino Tesfahun Tsegaye ${ }^{3}$, Amare Tariku', Terefe Derso ${ }^{4}$, Solomon Mekonnen Abebe ${ }^{4,5}$ and Mulugeta Bayisa Chala ${ }^{6}$

\begin{abstract}
Background: Failure to provide adequate sanitation services to all people is perhaps the greatest development failure. Globally, billions of people have no access to improved sanitation facilities. Though the link between sanitation and childhood morbidities is established globally, the evidence is limited in rural parts of Ethiopia. This survey was, therefore, designed to determine the prevalence of common childhood morbidities and to identify sanitation predictors in rural parts of northwest Ethiopia.

Methods: A re-census reconciliation, which is a cross-sectional design, was employed from October to December 2014. All households found in the research and demographic sites were included as study subjects. A questionnaire and an observational checklist were used to collect data. Households' sanitation performances, house type, illumination, household energy sources, water supply, and waste management were assessed. The occurrence of childhood morbidities was determined from the occurrence of one or more water, sanitation, and hygiene (WASH) preventable diseases. Multivariable binary logistic regression analysis was done to identify the association of sanitation factors with childhood morbidities on the basis of adjusted odds ratio (AOR) with $95 \%$ confidence interval (Cl) and $p$ value $<0.05$

Results: About 575 (7.00\%) of under-five children had hygiene- and sanitation-related diseases. Gastrointestinal and respiratory health problems accounted for 287 (49.91\%) and 288 (50.09\%), respectively. Childhood morbidities among under-five children were associated with poor housing condition $[A O R=1.27,95 \% \mathrm{Cl}=(1.04,1.54)]$, dirty cooking energy sources $[A O R=1.52,95 \% \mathrm{Cl}=(1.22,1.89)]$, volume of water below $20 \mathrm{l} / \mathrm{p} / \mathrm{d}[\mathrm{AOR}=1.95,95 \% \mathrm{Cl}=(1.19,3.18)]$, and narrow-mouthed water storage containers $[A O R=0.73,95 \% \mathrm{Cl}=(0.56,0.96)]$.

Conclusion: A significant proportion of under-five children had childhood morbidities in the study area. Housing condition, cooking energy sources, volume of water collected, and type of water storage containers were factors associated with the occurrence of childhood morbidities. Enabling the community to have the access to a safe and continuous supply of water and proper disposal of wastes, including excreta, is necessary with particular emphasis to the rural communities and semi-urban areas to reduce the occurrence of childhood morbidities.
\end{abstract}

Keywords: Housing condition, Waste management, Drinking water supply, Childhood morbidities, Dabat Health and Demographic Surveillance System

\footnotetext{
* Correspondence: zemichael12@gmail.com

1Department of Environmental and Occupational Health and Safety, Institute

of Public Health, College of Medicine and Health Sciences, University of

Gondar, Gondar, Ethiopia

Full list of author information is available at the end of the article
}

(c) The Author(s). 2019 Open Access This article is distributed under the terms of the Creative Commons Attribution 4.0 International License (http://creativecommons.org/licenses/by/4.0/), which permits unrestricted use, distribution, and reproduction in any medium, provided you give appropriate credit to the original author(s) and the source, provide a link to the Creative Commons license, and indicate if changes were made. The Creative Commons Public Domain Dedication waiver (http://creativecommons.org/publicdomain/zero/1.0/) applies to the data made available in this article, unless otherwise stated. 


\section{Background}

Access to adequate water and sanitation is a fundamental need and a human right to all citizens. Increasing coverage of these essential services is vital for the dignity and health of all people and will significantly contribute to population welfare as well as the wealth and stability of countries. The failure to provide adequate sanitation services to all people is perhaps the greatest developmental failure [1].

Poor water, sanitation, and hygiene conditions cause a range of gastrointestinal and respiratory health problems, many of which are life-threatening. Each year, at least three million children under the age of five die due to environment-related diseases. Acute respiratory infections (ARIs) annually kill an estimated two million children under the age of five. As much as $60 \%$ of acute respiratory infections worldwide are related to environmental conditions [2]. Intestinal infectious diseases are also the most common cause of death among children [3]. Diarrhea and pneumonia are the most deadly gastrointestinal and respiratory health problems. In 2010, the global and regional estimate of the burden of diseases indicated that 7.6 million deaths among children younger than five years of age were caused due to sanitationrelated infections. Among these deaths, 1.07 million $(14.10 \%)$ and 0.75 million (9.90\%) deaths were attributable to pneumonia and diarrheal causes, respectively. The greatest causes for these infections were water-, hygiene-, and sanitation-related [4].

Though the link between sanitation and childhood morbidities is established globally, the evidence is limited in rural parts of Ethiopia. This re-census was, therefore, designed to determine the burden of childhood morbidities and to identify sanitation predictors in rural parts of northwest Ethiopia, at Dabat Health and Demographic Surveillance System Sites.

\section{Methods}

\section{Study design and settings}

This cross-sectional study is a re-census employed for the purpose of reconciliation of the Dabat Health and Demographic Surveillance System (DHDSS). The surveillance system has been running since 1996 and has been collecting information on vital events (like birth, death, migration, and pregnancy registrations) and hygiene and sanitation conditions by updating every six months. The site is located in the Dabat district in the northwest part of Ethiopia. Dabat district was initially selected purposively as a surveillance site for its unique three climatic conditions, namely Dega (high land and cold), Woina Dega (midland and temperate), and Kolla (low land and hot). The choice was made with the assumption that there would be differences in morbidity and mortality in the different climatic areas. In 2014, the district had an estimated population size of 173,052 living in 26 rural and four semi-urban kebeles (the smallest administrative unit in Ethiopia). The DHDSS covers thirteen selected kebeles (four semi-urban and nine rural kebeles). A total of 67,385 people were living in the selected kebeles [5].

\section{Description of data collection process}

Data about under-five children were extracted from DHDSS database which were collected by a re-census for the purpose of reconciliation. A re-census was employed in thirteen purposively selected kebeles. Kebeles were initially selected from three different agro-ecological zones for the purpose of showing differences in morbidity and mortality in the different climatic areas. Hence, we employed a re-census, and data collectors visited all the households in the selected kebeles. Data were collected using a pre-tested structured interviewer-administered questionnaire and an observational checklist. The living environment and housing conditions were observed, and photo cameras were used to take pictures by taking participants' consent. Training was given for data collectors and field supervisors about the data collection tools, data collection procedures, and data collectors' ethics. Mothers were interviewed about the most common childhood morbidities of their children and sanitation condition. Supervisors had also checked the completeness of all the filled questionnaires.

\section{Measurement of variables}

Childhood morbidity, the primary outcome variable of this study, was defined as the occurrence of one or more gastrointestinal health problems (such as diarrhea, vomiting, and abdominal pain) and respiratory health problems (such as common cold, cough, pneumonia, asthma, and other sanitation-related respiratory problems). Childhood diarrheal disease was defined as having three or more loose or watery stools in $24 \mathrm{~h}$ [6]. The occurrence of the symptoms of the above morbidities in the past 2-week period was taken by asking the mothers/guardians. We used the local names of each disease to make clear for the mothers or guardians. Moreover, for the children who visited health institution, we checked the medication history to identify the specific types of diseases, and we asked the mothers or guardians to tell us the name of the diseases confirmed by the physicians. The sanitation predictor variables like housing condition, household energy sources, household light sources, domestic wastewater management practice, household's solid waste management practice, household's defecation practices, and drinking water supply system were defined and classified based on the minimum or indicators for access to basic sanitation set by the World Health Organization (WHO) and United Nations Children's Fund (UNICEF) [7]. A housing condition was taken as good 
housing if the roof is covered by corrugated iron sheet (CIS); the floor is timber or concrete; rooms had two or more windows; the illumination system is adequate; and the energy was from clean sources like electricity. Illumination system was taken as good if the intensity of light is adequate and not emitting pollutants to the room like electricity and solar. Household cooking energy was taken as relatively clean energy if the source has no or minimal pollutants such as electric power, kerosene, and coal. Drinking water sources were taken as protected if the sources are protected from animal contact, flooding, and wind such as protected well, protected spring, protected rain catchment, and tap water. Households' handwashing practice was taken as good if all family members washed hands after visiting the toilet, changing the baby's diaper, or touching wastes and before eating and food preparation, otherwise taken as poor.

\section{Data management, processing, and analysis}

Data were entered to Household Registration System (HRS2) version 2.1 and analyzed using Stata version 14.0. Univariable binary logistic regression analysis was used to choose variables for the multivariable binary logistic regression analysis, and variables which had a $p$ value less than 0.2 by the univariable analysis were put into the final model. Variables which had significant association were identified on the basis of AOR with $95 \% \mathrm{CI}$ and $p$ value $<$ 0.05 . Pearson's chi-square goodness of fit test was used to check model fitness.

Principal component analysis was used to determine the wealth index of rural households using asset data. In the final model, the common factor scores were summed and ranked into poorest quintile, second quintile, third quintile, fourth quintile, and richest quintile.

\section{Results}

\section{Socio-demographic characteristics}

A total of 8219 under-five children were included in this study. Of these children, 4149 (50.48\%) were male. Four thousand eight hundred eighty-nine (59.48\%) children were aged between 25 and 59 months. The overwhelming majority, 6491 (78.98\%), of children were rural residents. Almost all, 8143 (99.08\%), of the mothers interviewed were illiterate. One thousand seven (12.25\%) of the households were the poorest by their economic status (Table 1).

\section{Housing condition}

Six thousand one hundred seventy (75.07\%) of the study participants lived in poor housing condition. Almost all, 8114 (98.72\%), of the houses were earthen floor, and 2381 (28.97\%) of the residential buildings were tukul, a house built with wood and grass. Five thousand eight hundred two (70.59\%) of the residential buildings had no window(s).
Table 1 Demographic information of under-five children in DHDSS sites, Dabat, northwest Ethiopia, October to December 2014

\begin{tabular}{lll}
\hline Variables & Frequency & Percent \\
\hline Sex of the child & & \\
Male & 4149 & 50.48 \\
Female & 4070 & 49.52 \\
Age of the child in months & & \\
0-6 & 752 & 9.15 \\
7-12 & 895 & 10.89 \\
13-24 & 1683 & 20.48 \\
25-59 & 4889 & 59.48 \\
Mothers' or guardians' education status & & \\
Illiterate & 8143 & 99.08 \\
Primary school (grades 1-8) & 44 & 0.54 \\
Secondary school (grades 9-12) and above & 32 & 0.39 \\
Economic status of the household & & \\
Poorest quintile & 1007 & 12.25 \\
Second quintile & 1567 & 19.07 \\
Third quintile & 1893 & 23.03 \\
Fourth quintile & 1870 & 22.75 \\
Richest quintile & 1882 & 22.90 \\
Residence of the child & & \\
Semi-urban & 1728 & 21.02 \\
Rural & 6491 & 78.98 \\
\hline
\end{tabular}

The general illumination system in 6323 (76.93\%) houses was poor. Seven hundred forty-three (9.04\%) of the households used open fire as a light source. The majority, 6897 (83.92\%), of the households utilized dirty cooking energy, and fire wood was the commonest source (Table 2).

\section{Water supply}

More than half, 4979 (60.58\%), of the households fetched drinking water from unprotected sources. Unprotected spring was the commonest drinking water source in the study area, which accounted for 3409 (41.48\%). Two thousand one hundred fifty-two (26.18\%) of the households traveled more than 30-min round trip to fetch water, and almost all 8070 (98.19\%) collected 20 $\mathrm{l} / \mathrm{p} / \mathrm{d}$ and below. Seven thousand seventy-one (86.03\%) of the households used narrow-mouthed containers to store drinking water. Six hundred seventy-nine (8.26\%) of the households treated drinking water at home. Sedimentation, 451(66.42\%), was the commonest homebased water treatment method in the area (Table 3).

\section{Waste management}

In the study area, 2376 (28.91\%) of the households used any type of latrine to defecate. Of the households who 
Table 2 Housing condition of study participants in DHDSS sites, Dabat, northwest Ethiopia, October to December 2014

\begin{tabular}{|c|c|c|}
\hline Characteristics of housing & Frequency & Percent \\
\hline \multicolumn{3}{|l|}{ Overall housing condition } \\
\hline Good & 2049 & 24.93 \\
\hline Not good & 6170 & 75.07 \\
\hline \multicolumn{3}{|l|}{ Roof construction } \\
\hline Wood and grass & 2381 & 28.97 \\
\hline Corrugated iron sheet & 5838 & 71.03 \\
\hline \multicolumn{3}{|l|}{ Floor type } \\
\hline Earthen floor & 8114 & 98.72 \\
\hline Concrete or cement floor & 105 & 1.28 \\
\hline \multicolumn{3}{|l|}{ Availability of at least one window } \\
\hline No & 5802 & 70.59 \\
\hline Yes & 2417 & 29.41 \\
\hline \multicolumn{3}{|l|}{ Illumination of the house } \\
\hline Good & 1896 & 23.07 \\
\hline Not good & 6323 & 76.93 \\
\hline \multicolumn{3}{|l|}{ Light sources (multiple sources) } \\
\hline Electricity & 1896 & 23.07 \\
\hline Kerosene lamp & 11 & 0.13 \\
\hline Sprite or Kuraz & 61 & 0.74 \\
\hline Flashlight & 6213 & 75.59 \\
\hline Open fire or wood & 743 & 9.04 \\
\hline Candle & 31 & 0.38 \\
\hline Solar & 13 & 0.16 \\
\hline \multicolumn{3}{|l|}{ Cooking energy sources (multiple sources) } \\
\hline Wood & 6845 & 83.28 \\
\hline Animal dung & 6700 & 81.52 \\
\hline Plant leaves/seed & 1204 & 14.65 \\
\hline Charcoal & 1267 & 15.42 \\
\hline Kerosene & 8 & 0.10 \\
\hline Electricity & 47 & 0.57 \\
\hline \multicolumn{3}{|l|}{ Condition of household's cooking energy } \\
\hline Dirty (biomass fuel) & 6897 & 83.92 \\
\hline Relatively clean (charcoal, kerosene, and electricity) & 1322 & 16.08 \\
\hline
\end{tabular}

used latrine, 2140 (90.07\%) households used traditional pit latrine. Seven thousand three hundred forty $(89.31 \%)$ and $7030(85.53 \%)$ respectively disposed domestic wastewater and solid wastes in open field. The handwashing practice of $6416(78.06 \%)$ households was poor (Table 4 )

\section{Childhood morbidities}

About 575 (7.00\%) of under-five children had hygieneand sanitation-related diseases. Gastrointestinal and respiratory health problems accounted for 287 (49.91\%) and 288 (50.09\%), respectively. Of the children who had hygiene- and sanitation-related diseases, 83 (14.43\%) children had both gastrointestinal and respiratory health problems.

\section{Sanitation predictors of childhood morbidities}

Housing condition, household cooking energy sources, household's solid waste management practice, household's domestic wastewater management practice, household's defecation practices, drinking water sources, type of drinking water storage container, home-based water treatment, and volume of water daily collected were the variables fitted in the univariable binary logistic regression model. 
Table 3 Drinking water sources and home water handling among households in DHDSS sites, Dabat, northwest Ethiopia, October to December 2014

\begin{tabular}{|c|c|c|}
\hline Variables & Frequency & Percent \\
\hline \multicolumn{3}{|c|}{ Water sources (multiple sources) } \\
\hline Tap water & 1683 & 20.48 \\
\hline Protected spring & 851 & 10.35 \\
\hline Protected well & 750 & 9.13 \\
\hline Unprotected spring & 3409 & 41.48 \\
\hline Unprotected well & 95 & 1.16 \\
\hline River & 1789 & 21.77 \\
\hline \multicolumn{3}{|c|}{ Condition of drinking water sources } \\
\hline Unprotected & 4979 & 60.58 \\
\hline Protected & 3240 & 39.42 \\
\hline \multicolumn{3}{|c|}{ Time taken to collect water (round trip) } \\
\hline$\leq 30 \mathrm{~min}$ & 6067 & 73.82 \\
\hline$>30 \min$ & 2152 & 26.18 \\
\hline \multicolumn{3}{|l|}{ Volume of water collected } \\
\hline$\leq 20 \mathrm{l} / \mathrm{p} / \mathrm{d}$ & 8070 & 98.19 \\
\hline$>20 \mathrm{l} / \mathrm{p} / \mathrm{d}$ & 149 & 1.81 \\
\hline \multicolumn{3}{|c|}{ Type of water storage container } \\
\hline Narrow mouthed & 7071 & 86.03 \\
\hline Wide mouthed & 1148 & 13.97 \\
\hline \multicolumn{3}{|c|}{ Home-based water treatment } \\
\hline Yes & 679 & 8.26 \\
\hline No & 7540 & 91.74 \\
\hline \multicolumn{3}{|c|}{ Home-based water treatment methods (multiple methods) ( $n=67 \mathrm{~s}$} \\
\hline Boiling & 120 & 17.67 \\
\hline Chlorination & 68 & 10.01 \\
\hline Cloth filtration & 67 & 9.87 \\
\hline Sand or clay filtration & 40 & 5.89 \\
\hline Sedimentation & 451 & 66.42 \\
\hline
\end{tabular}

I/p/d liter per person per day

The variables having $p$ value less than $20 \%$ were housing condition, household cooking energy sources, household's defecation practices, type of drinking water storage container, and volume of water daily collected, which were selected for multivariable binary logistic regression analysis. By the multivariable binary logistic regression analysis, housing condition, household cooking energy sources, type of drinking water storage container, and volume of water daily collected were statistically associated with childhood morbidities (Table 5).

This survey revealed that the occurrence of childhood morbidities was associated with housing condition. The odds of occurrence of morbidities was 1.27 times higher among children who lived in poor housing condition
Table 4 Waste management practices in DHDSS sites, Dabat, northwest Ethiopia, October to December 2014

\begin{tabular}{lll}
\hline Variables & Frequency & Percent \\
\hline Household's defecation practices & 5843 & 71.09 \\
$\quad$ Open defecation & 2376 & 28.91 \\
$\quad$ Any type of latrine & & \\
Types of latrine commonly used ( $n=2376)$ & 2140 & 90.07 \\
Traditional pit latrine & 224 & 9.43 \\
VIP latrine & 12 & 0.51 \\
Septic tank & 7340 & 89.31 \\
Household's domestic wastewater handling practice & 10.69 \\
Open field & 879 & \\
Sock pit & & 85.53 \\
Household's solid waste handling practice & 7030 & 14.47 \\
Open field & 1189 & \\
Either burial or burning & & 21.94 \\
Household's handwashing practice & 1803 & 78.06 \\
Good & 6416 & \\
Poor
\end{tabular}

VIP ventilated improved pit latrine

compared with children who lived in good housing condition $[\mathrm{AOR}=1.27,95 \% \mathrm{CI}=(1.04,1.54)]$.

This study revealed that household cooking energy sources were significantly associated with childhood morbidities. The occurrence of childhood morbidities was 1.52 times to be higher among children of households with dirty cooking energy sources compared with children of households with relatively clean energy sources $[\mathrm{AOR}=1.52,95 \% \mathrm{CI}=(1.22,1.89)]$.

As depicted by this survey, childhood morbidities were statistically associated with the volume of water daily collected. The odds of having childhood morbidities was 1.95 times higher among households who collected 20 l/ $\mathrm{p} / \mathrm{d}$ and below $[\mathrm{AOR}=1.95,95 \% \mathrm{CI}=(1.19,3.18)$. The current study had also discovered that the type of drinking water storage containers was associated with childhood morbidities. The odds of childhood morbidities was $27 \%$ less among children whose families stored drinking water in narrow-mouthed containers $[\mathrm{AOR}=$ $0.73,95 \% \mathrm{CI}=(0.56,0.96)]$.

\section{Discussion}

The 2-week period prevalence of childhood morbidities was 7.00 per hundred under-five children. The report of this re-census was lower than the reports of different community-based surveys like in Dabat, Ethiopia (33.70\%) [8]; in Kenya (30.00\%) [9]; in Wardha, India (59.90\%) [10]; in Maharastra, India (34.70\%) [11]; in Kolkata, India (52.45\%) [12]; and in Tamil Nadu, India (71.00\%) [13]. The lower prevalence of childhood morbidities in this 
Table 5 Sanitation predictors of childhood morbidities among under-five children in DHDSS sites, Dabat, northwest Ethiopia, October to December 2014

\begin{tabular}{|c|c|c|c|c|}
\hline \multirow[t]{2}{*}{ Sanitation predictors } & \multicolumn{2}{|c|}{ Childhood morbidities } & \multirow{2}{*}{$\begin{array}{l}\text { COR with 95\% } \\
\mathrm{Cl}\end{array}$} & \multirow[t]{2}{*}{ AOR with $95 \% \mathrm{Cl}$} \\
\hline & Yes & No & & \\
\hline \multicolumn{5}{|l|}{ Housing condition } \\
\hline Not good & 412 & 5758 & $1.21(1.0,1.46)$ & $1.27(1.04,1.54)^{*}$ \\
\hline Good & 163 & 1886 & 1 & \\
\hline \multicolumn{5}{|c|}{ Household cooking energy source } \\
\hline Dirty sources & 449 & 6448 & $1.51(1.23,1.86)$ & $1.52(1.22,1.89)^{* * *}$ \\
\hline Relatively clean sources & 126 & 1196 & 1 & \\
\hline \multicolumn{5}{|l|}{ Human excreta management } \\
\hline Open field & 443 & 6085 & $1.16(0.95,1.42)$ & $1.16(0.93,1.44)$ \\
\hline Any type of latrine & 132 & 1559 & 1 & \\
\hline \multicolumn{5}{|l|}{ Volume of water collected } \\
\hline$\leq 20 \mathrm{l} / \mathrm{p} / \mathrm{d}$ & 555 & 7515 & $2.10(1.30,3.39)$ & $1.95(1.19,3.18)^{* *}$ \\
\hline$>20 \mathrm{l} / \mathrm{p} / \mathrm{d}$ & 20 & 129 & & \\
\hline \multicolumn{5}{|l|}{ Type of water storage container } \\
\hline Narrow-mouthed container & 506 & 6565 & $0.83(0.641 .08)$ & $0.73(0.56,0.96)^{*}$ \\
\hline Wide-mouthed container & 69 & 1079 & & \\
\hline
\end{tabular}

$A O R$ adjusted odds ratio, $C I$ confidence interval; $C I S$ corrugated iron sheet, COR crude odds ratio, $I / p / d$ liter per person per day

*Statistically significant at $p<0.05$

**Statistically significant at $p<0.01$

***Statistically significant at $p<0.001$

study compared with the above findings might be due to seasonal variation.

The current survey found that the prevalence of gastrointestinal and respiratory health problems was $49.91 \%$ and $50.09 \%$, respectively. Even though the prevalence for specific diseases was not exactly the same, other studies had also identified that diarrhea and respiratory problems were the major causes [8,9]. A study done at demographic and health surveillance system in rural western Kenya reported that acute respiratory infections and diarrhea were the major causes of underfive morbidity [14].

This re-census had revealed that housing condition was associated with the occurrence of childhood morbidities. The result indicated that poor housing condition increases the likelihood of occurrence morbidities. This is due to poorly designed, constructed, and maintained buildings that create favorable condition for multiplication of disease-causing microorganisms and also contain toxic indoor air pollutants. Earthen floor and inadequate ventilation also increase interior moisture. Damp houses provide favorable conditions for microorganisms, molds, and vectors, which play roles in disease occurrence and transmission. Other similar studies also supported this fact [15-19].

This study showed that children of households with dirty cooking energy sources had more odds to develop morbidities. The association of dirty cooking energy usage and childhood morbidities can be due to the fact that dirty energy sources including wood, animal dung, or crop residues produce particulates, carbon monoxide, and other indoor pollutants, which can cause or aggravate ARIs, including upper respiratory infections such as colds and sore throats, and lower respiratory infections such as pneumonia. ARIs can also increase the risk of measles, malaria, and other diseases [20-22].

The occurrence of childhood morbidities was statistically associated with the volume of water daily collected. The prevalence of childhood morbidities was higher in households who collected water $20 \mathrm{l} / \mathrm{p} / \mathrm{d}$ and below. This finding is in line with findings of other similar studies $[23,24]$. This might be due to the fact that where the basic access service level has not been achieved, hygiene cannot be assured, which increases the occurrence and transmission of feco-oral diseases including respiratory health problems [23, 24].

The current study had discovered that the likelihood of occurrence of childhood morbidities was $27 \%$ less among children in households who stored water in narrow-mouthed containers. This can be justified that the safety of water stored in a narrow-mouthed container was higher than in wide-mouthed containers like buckets because contamination through dipping in smaller vessels like cups and jugs was minimized. Wide- 
mouthed containers are more prone to contamination because of their large open surface area. Other similar studies had also reported similar findings [25, 26].

\section{Limitation of the study}

The occurrence of childhood morbidities was determined based on the report of mothers or head of the family. It was not confirmed by physicians. Due to this phenomenon, the current study might be affected by social desirability bias. The other limitation of this study was that separate analysis based on the nature and mechanisms of childhood morbidities (i.e., gastrointestinal health problems and respiratory health problems) was not done because of inadequate number of cases. Moreover, this study did not show the burden of childhood morbidities in different seasons of a year. In fact, socio-economic variables have effects on childhood morbidity, and we did not include them in the analysis. Hence, health data are limited in rural parts of Ethiopia, and with the limitations it has, this study will have a contribution to the policy makers and communities to design sanitation improvement and morbidity reduction strategies.

\section{Conclusions}

A significant proportion of under-five children had poor water-, sanitation-, and hygiene-related morbidities in the study area. Housing condition, cooking energy sources, volume of water collected, and type of water storage container were identified as factors associated with the occurrence of childhood morbidities. There was a good start towards excreta management and water supply in the study areas; however, the quality of the facilities was not in a position of ensuring sanitation and disease prevention. Enabling the community to have access to safe and continuous supply of water and proper disposal of wastes including excreta is necessary with particular emphasis to the rural communities and semi-urban areas.

\begin{abstract}
Abbreviations
AOR: Adjusted odds ratio; ARIS: Acute respiratory infections; Cl: Confidence interval; CIS: Corrugated iron sheet; COR: Crude odds ratio; DHDSS: Dabat Health and Demographic Surveillance System; HRS2: Household Registration System; I/p/d: Liter per person per day; p: Proportion or prevalence; TB: Tuberculosis; UNICEF: United Nations Children's Fund; VIP: Ventilated improved pit latrine; WASH: Water, sanitation, and hygiene; WHO: World Health Organization
\end{abstract}

\section{Acknowledgements}

The authors are pleased to acknowledge data collectors, field supervisors, and households found in the DHDSS sites for their unreserved contribution to the success of the survey. The authors would like to extend their gratitude for Dabat district administrators for their facilitation.

\section{Authors' contributions}

All the authors actively participated during conception of the research issue, development of a research proposal, data collection, analysis and interpretation, and writing various parts of the research report. ZG had analyzed the data. GAB, MY, KA, TA, and SMA had designed the survey. GAA, $A T T, A T, T D$, and $M B$ had revised the manuscript. This final manuscript is prepared by ZG. All the authors read and approved the final manuscript.

\section{Funding}

The study was funded by PEPFAR - Centers for Disease Control and Prevention (CDC) through the Ethiopian Public Health Association (EPHA) in accordance with the EPHA-CDC Cooperative Agreement No.

NU22GGH001039-04-00 and Gondor University. However, the findings and conclusions in this manuscript are those of the author(s) and do not necessarily represent the official position of the Centers for Disease Control and Prevention/Agency for Toxic Substances and Disease Registry.

\section{Availability of data and materials}

Data will be made available upon request from the primary author.

Ethics approval and consent to participate

Ethical clearance was obtained from the institutional review board of the University of Gondar, and official letter was submitted to the town

administrators. The observational checklist or questionnaire was proved not to affect the morale and personality of study subjects. The materials used for this research purpose had no any health hazards. There is no risk in participating in this research project, and the collected data were used only for the research purpose. Hence, most of the subjects are illiterate, verbal informed consent was obtained from each study subject, and study subjects were informed about the objective of the study. Data were collected after getting informed verbal consent. Privacy during the interview was ensured, and confidentiality was granted.

\section{Consent for publication}

This manuscript does not contain any individual person's data.

\section{Competing interests}

The authors declare that they have no competing interests.

\section{Author details}

${ }^{1}$ Department of Environmental and Occupational Health and Safety, Institute of Public Health, College of Medicine and Health Sciences, University of Gondar, Gondar, Ethiopia. ${ }^{2}$ Department of Health Service Management and Health Economics, Institute of Public Health, College of Medicine and Health Sciences, University of Gondar, Gondar, Ethiopia. ${ }^{3}$ Department of

Epidemiology and Biostatistics, Institute of Public Health, College of Medicine and Health Sciences, University of Gondar, Gondar, Ethiopia. ${ }^{4}$ Department of Human Nutrition, Institute of Public Health, College of Medicine and Health Sciences, University of Gondar, Gondar, Ethiopia. ${ }^{5}$ Dabat Research Center Health and Demographic Surveillance System, Institute of Public Health, College of Medicine and Health Sciences, University of Gondar, Gondar, Ethiopia. ${ }^{6}$ Department of Physiotherapy, College of Medicine and Health Sciences, University of Gondar, Gondar, Ethiopia.

Received: 22 June 2018 Accepted: 30 May 2019

Published online: 13 June 2019

\section{References}

1. Fewtrell L, Kaufmann RB, Kay D, Enanoria W, Haller L, Colford JM. Water, sanitation, and hygiene interventions to reduce diarrhoea in less developed countries: a systematic review and meta-analysis. Lancet Infect Dis. 2005;5: 42-52.

2. World Health Organization (WHO). Global plan of action for Children's health and the environment (2010-2015). Available at http://www.who.int/ ceh/cehplanaction10_15.pdf. Accessed 17 Oct 2018.

3. HME. Global, national burden of diseases, injuries among children and adolescents. Available at http://www.healthdata.org/news-release/globalnational-burden-diseases-injuries-among-children-and-adolescents. Accessed 17 Oct 2018.

4. Liu L, Johnson HL, Cousens S, Perin J, Scott S, Lawn JE, et al. Global, regional, and national causes of child mortality: an updated systematic analysis for 2010 with time trends since 2000. Lancet. 2012;379(9832): 2151-61.

5. Kebede Y, Andarge G, Melesse T, Azmeraw T, Tadesse T, Tefera Y, et al. Population dynamics in Dabat health and demographic surveillance system sites, Dabat district, northwest Ethiopia: a four year serveillance report (2009 to 2012). Ethiop J Health Biomed Sci. 2015;7:1-42.

6. UNICEF/WHO. Diarrhoea: why children are still dying and what can be done. Geneva: The United Nations Children's Fund/World Health 
Organization; 2009. Availlable at www.unicef.org/.../Final_Diarrhoea_ Report_October_2009_final.pdf. Accessed 18 Oct 2018

7. World Health Organization and United Nations Children's Fund Joint Monitoring Programme for Water Supply and Sanitation (JMP). Progress on drinking water and sanitation: special focus on sanitation. New York and Geneva: UNICEF and WHO; 2008. Available at www.wssinfo.org/fileadmin/ user_upload/resources/1251794333-JMP_08_en.pdf. Accessed 20 July 2018

8. Tessema T, Hailu S, Anberbir S, Mitikie G. Household illness prevalence and its determinants in the under-five children. Ethiop J Health Dev. 2001;15(3):173-8.

9. Masibo PK, Makoka D. Trends and determinants of undernutrition among young Kenyan children: Kenya Demographic and Health Survey; 1993, 1998, 2003 and 2008-2009. Public Health Nutr. 2012;15(9):1715-27.

10. Deshmukh P, Dongre A, Sinha N, Garg B. Acute childhood morbidities in rural Wardha: some epidemiological correlates and health care seeking. Indian J Med Sci. 2009;63(8):345-54.

11. Giri V, Dhage V, Zodpey S, Ughade S, Biranjan J. Prevalence and pattern of childhood morbidity in a tribal area of Maharastra. Indian J Public Health. 2008;52(4):207-9.

12. Mondal K, Baidya S, Dasgupta U. Study of morbidity and nutritional profile among under five children in an urban slum, Kolkata. IOSR J Dent Med Sci (IOSR-JDMS). 2016;15(8):1-3.

13. Raja RV, Rubini MS, Hemalatha K. Prevalence and determinants of morbidity among under five children in rural area of Tamil Nadu. Int J Interdiscip Multidiscip Stud (IIIMS). 2016;3(4):5-10.

14. Adazu K, Lindblade KA, Rosen DH, Odhiambo F, Ofware P, Kwach J, et al. Health and demographic surveillance in rural western Kenya: a platform for evaluating interventions to reduce morbidity and mortality from infectious diseases. Am J Trop Med. 2005;73(6):1151-8.

15. Blomquist G, Gyntelberg F, Järvholm B, Malmberg P, Nordvall L, Nielsen A, et al. Dampness in buildings and health. Indoor Air. 2001;11:72-86.

16. Aylin P, Morris S, Wakefield J, Grossinho A, Jarup L, Elliott P. Temperature, housing, deprivation and their relationship to excess winter mortality in Great Britain, 1986-1996. Int J Epidemiol. 2001;30(5):1100-8.

17. Fisk WJ, Lei-Gomez Q, Mendell MJ. Meta-analyses of the associations of respiratory health effects with dampness and mold in homes. Indoor Air. 2007;17(4):284-96

18. Breysse P, Farr N, Galke W, Lanphear B, Morley R, Bergofsky L. The relationship between housing and health: children at risk. Environ Health Perspect. 2004;112(15):1583-8.

19. Bratt RG. Housing and family well-being. Hous Stud. 2002;17(1):13-26.

20. Fullerton DG, Bruce N, Gordon SB. Indoor air pollution from biomass fue smoke is a major health concern in the developing world. Trans R Soc Trop Med Hyg. 2008;102(9):843-51.

21. Arbex MA, Cançado JED, Pereira LAA, Braga ALF, Saldiva PHN. Biomass burning and its effects on health. J Bras Pneumol. 2004;30(2):158-75.

22. Chakraborty D, Mondal NK, Datta JK. Indoor pollution from solid biomass fuel and rural health damage: a micro-environmental study in rural area of Burdwan, West Bengal. Int J Sustain Built Environ. 2014;3(2):262-71.

23. Stelmach RD, Clasen T. Household water quantity and health: a systematic review. Int J Environ Res Public Health. 2015;12:5954-74.

24. Thomas T, Ritter T, Bruden D, Bruce M, Byrd K, Goldberger R, et al. Impact of providing in-home water service on the rates of infectious diseases: results from four communities in Western Alaska. J Water Health. 2016;14(1):132-41.

25. Kioko KJ, Obiri JF. Household attitudes and knowledge on drinking water enhance water hazards in peri-urban communities in Western Kenya, Jàmbá. J Disaster Risk Stud. 2012;4(1):1-5.

26. Clasen T, Saeed TF, Boisson S, Edmondson P, Shipin O. Household water treatment using sodium dichloroisocy anurate ( $\mathrm{NaDCC}$ ) tablets: a randomized, controlled trial to assess microbiological effectiveness in Bangladesh. Am J Trop Med Hyg. 2007;76(1):187-92.

\section{Publisher's Note}

Springer Nature remains neutral with regard to jurisdictional claims in published maps and institutional affiliations.

\section{Ready to submit your research? Choose BMC and benefit from}

- fast, convenient online submission

- thorough peer review by experienced researchers in your field

- rapid publication on acceptance

- support for research data, including large and complex data types

- gold Open Access which fosters wider collaboration and increased citations

- maximum visibility for your research: over $100 \mathrm{M}$ website views per year

At BMC, research is always in progress.

Learn more biomedcentral.com/submissions 